\title{
Algunas notas sobre la localización del viñedo en la Jacetania occidental durante los siglos IX al XIII
}

\author{
M. ${ }^{a}$ VICTORIA AZCÁRATE LUXÁN
}

\section{INTRODUCCIÓN}

El presente trabajo forma parte de un proyecto general de estudio de la localización de las áreas vitícolas del Pirinero aragonés durante la Edad Media '.

El área que ahora nos ocupa, cuna del primitivo Condado de Aragón, comprende el sector occidental de la actual comarca oscense de la Jacetania, que abarca la cuenca del río Majones, la cuenca del río Veral (Valle de Anso), la cuenca del río Aragón Subordán (Valle de Hecho), y el tramo correspondiente de la depresión longitudinal intrapirenaica - la Canal de Berdún-; es decir, el espacio comprendido por los actuales

1 Azcarate Luxan, M. V., "Contribución al estudio del viñedo en el Pirineo Central y Occidental durante el siglo xI según documentación real», en Studia Humanistica. Anuario de la Facultad de Filosofía y Letras. UNED. Vol. I, p. 81-113 (1976).

-: «El viñedo en Ribagorza durante los siglos XI-XIl y XII"». Boletin de la Real Sociedad Geográfica. XXIII Congreso Internacional de Geografía. Moscú, p. 37-47 (1976).

-: "La localización del viñedo durante los siglos $x$ y $\times 1$, según documentación del Monasterio de San Martín de Albelda». Boletín de la Real Sociedad Geográfica. XXIV Congreso Internacional de Geografia. Tokyo, p. 1-15 (1979).

-: “El viñedo en el Alto Gállego durante los siglos XI al XIII según documentación del Monasterio de San Andrés de Fanlo». I Congreso Internacional de Historia de los Pirineos. Cervera (Lérida). En prensa (1988). 
municipios de Fago, Ansó, Valle de Hecho, Canal de Berdún, Puente la Reina de Jaca y Bailo.

Para su estudio hemos utilizado las siguientes fuentes documentales:

- "Cartulario de Siresa" (Ubieto, 1960).

- "Cartulario de San Juan de la Peña" (Ubieto, 1962 y 1963).

- “Colección Diplomática de San Juan de la Peña" (Magallón, 1903-1904).

- «Libro Gótico o Cartulario de San Juan de la Peña" (CANellasUsÓN, 1935).

- "Colección Diplomática de la Catedral de Huesca" (DuRáN, 19651969).

- «Documentos correspondientes al reinado de Ramiro I desde 1034 hasta 1063" (IBARRA, 1904).

- «Documentos correspondientes al reinado de Sancho Ramírez, desde 1063 hasta 1094". Documentos reales (SalarRullana, 1907).

- «Documentos correspondientes al reinado de Sancho Ramírez, desde 1063 hasta 1094». Documentos particulares (IBARRA, 1913).

- «El Libro de la Cadena del Concejo de Jaca. Documentos Reales, Episcopales y Municipales de los siglos X, XI, XII, XIII, XIV》 (SANGORRIN, 1920).

- "Jaca: Documentos Municipales" (UBIETo, 1975).

- "Colección Diplomática de San Andrés de Fanio" (CANellas, 1964).

- Cartulario de Santa Cruz de la Serós" (UBIETo, 1966).

\section{TOPÓNIMOS CON VIÑEDOS MENCIONADOS EN EL SIGLO IX}

Entre las fuentes documentales consultadas tan sólo tres mencionan la existencia de viñedos en esta área; se trata de la Colección Diplomática de la Catedral de Huesca, el Cartulario de San Juan de la Peña y el Cartulario de Siresa. La mayoria son donaciones de diversas heredades 
(campos, viñas, huertos, etc.) efectuadas en su mayor parte a favor de San Pedro de Siresa. Este Monasterio está situado en la cuenca del Aragón Subordán (Valle de Hecho), cerca de la villa del mismo nombre, y fue fundado en el año 833 por el conde carolingio Galindo Aznárez I. Tras una etapa de esplendor, San Pedro de Siresa sufrió un largo período de decadencia a raíz de la incursión de Almanzor a principios del siglo $x$, cuyo ejército arrasó el Viejo Aragón sembrando el terror en los valles pirenaicos. En el año 1093 Sancho Ramírez dona San Pedro de Siresa al Monasterio de Montearagón (véase nota 18), y en la segunda mitad del siglo XII es incorporado a la Catedral de Jaca, convirtiéndose definitivamente en priorato (Durán, 1973: 17 y 89-92).

Así, en un documento fechado entre el año $814-839^{2}$ el conde Galindo y su esposa donan a dicho Monasterio lo comprendido desde Borbosse hasta Higirem, con todos sus pastos, viñas, etc. Berbués es un despoblado cercano a Sta. Engracia (Asso, 1947: 118; Ubieto, 1972: 57), mientras que Higirem es un topónimo cuya localización exacta es difícil precisar, si bien por el contexto seguramente se encontraría en la cuenca del río Aragón Subordán.

Años más tarde, el mismo Monasterio recibe otra donación de todas las viñas, tierras, villas, etc., que se encontraban desde Oledola hasta el propio Monasterio ${ }^{3}$. Según otra versión de la misma donación, dicho donante ofrece a San Pedro de Siresa ${ }^{4}$ todo to que tenía desde isxavierre Gayo hasta Aquatorta, con sus tierras, viñas, etc.; se trata de Javierregay y Aguatorta, ambos en la cuenca del río Aragón Subordán (Valle de Hecho).

De la primera mitad del siglo $1 \mathrm{x}^{5}$ data un inventario de las posesiones que tenía el Monasterio de San Pedro de Siresa, entre las que se mencionan varias viñas en Sebori. Este mismo documento, pero fechado en el siglo $x$, consta también en el Cartulario de Siresa ${ }^{6}$. Sebori es un topónimo acerca de cuya localización exacta hay dudas: según las fuen-

${ }^{2}$ Siresa, doc. 1. Catedral de Huesca, doc. 3 (fechado en el 833 y con alguna variante en la transcripción).

${ }^{3}$ Catedral de Huesca, doc. 7.

${ }^{4}$ Siresa, doc. 4. Se trata del mismo documento que el de la nota 3 , si bien por un problema de puntuación en la transcripción el viñedo se localiza en otro lugar. Así, según la Colección diplomática de la Catedral de Huesca el viñedo se cultivaba entre Oledola y el Monasterio de Siresa, mientras que según el Cartulario de Siresa, existian viñedos desde Javierregay hasta Aguatorta.

${ }^{5}$ Catedral de Huesca, doc. 4.

${ }^{6}$ Siresa, doc. 11. 
tes documentales más antiguas, el Viejo Aragón estaba formado por una serie de "pagus" de los que, entre otros, se conocen los nombres del "Seburicum" o "Suburicum", situados en el Valle de Hecho (Durán, 1973: 8). En este sentido, una de las primeras noticias de los Sebúricus se encuentra en la carta de San Eulogio de Córdoba al obispo Wilesindo tras su viaje por los Pirineros en el año 847, en la que menciona el Monasterio de San Pedro de Siresa, situado al pie del Pirineo, cerca de donde nace el río Aragón, que riega Séburis y Pamplona (Durán, 1988: 14). Así, parece ser que el nombre dado al Valle de Hecho durante los siglos I y $\times$ fue el de Seburis; lo que no sabemos con certeza es si con este nombre se designaba al núcleo principal del valle o si era el común de la zona geográfica en su conjunto (Durán, 1988: 100). Según Ubierto, 1972: 180, Sebori podría identificarse con Lebor, topónimo muy repetido a lo largo de la cuenca del río Aragón Subordán. También en este sentido, existe con el nombre de Lebúr un campo cerca de Embún (Elcock, 1949: 108). Incluso este mismo topónimo se encuentra en el nombre del actual río Aragón Subordán, que surca el Valle de Hecho. Hoy día, las últimas investigaciones realizadas sobre el tema se inclinan por la localización de este topónimo en el lugar donde se levantó el Monasterio de San Pedro de Siresa (Durán, 1988: 99).

Por último, en un interesante documento fechado a mediados de siglo ${ }^{7}$, unos particulares donan a San Martín de Cercito diversos bienes sitos en Arraise, entre ellos una tierra en la zona de la solana para plantar viñedo («donamus unam terram in Arraise, in parte solana, pro vinea ponenda"). Se trata de Arrés, lugar situado en la orilla izquierda del río Aragón, precisamente agrupado en la solana del monte Samitier, perteneciente hoy día al municipio de Bailo. La localización e incluso designación de topónimos según la orientación de la ladera se encuentra abundamentemente documentada (Alvar, 1949: 38).

En definitiva, el viñedo mencionado durante el siglo ix estaba situado fundamentalmente a lo largo de la cuenca del río Aragón Subordán (Valle de Hecho) y tímidamente aparece también en la depresión central pirenaica cuyas tierras margosas y arcillosas del Terciario son más favorables al desarrollo agrícola.

${ }^{7}$ San Juan de la Peña (Ubieto), doc. 5. 


\section{TOPÓNIMOS CON VIÑEDOS MENCIONADOS EN EL SIGLO X}

Son varias las fuentes documentales que testifican la existencia de viñedo durante el siglo $x$ en el área que ahora nos ocupa. Así, de mediados de siglo datan dos donaciones efectuadas al Monasterio de Labasal o Navasal (García Blanco, 1952: 7): en el año 947 el rey de Pamplona, García Sánchez I, en unión de Don Fortún, conde de Aragón, otorgan a dicho Monasterio seis mezquinos en el lugar de Binies, con sus huertos, campos, viñas, etc. ${ }^{8}$, y el mismo año la reina Toda, madre de García Sánchez I, ofrece a este mismo Monasterio los diezmos y primicias de la iglesia de Nuestra Sra. de Ardenes, tanto de tierras como de viñas, huertos, etc. ${ }^{9}$.

Del año 971 data una donación efectuada al Monasterio de San Pedro de Siresa, cuyo texto aparece en varias fuentes consultadas, con alguna variante en la transcripción ${ }^{10}$; se trata de una donación ofrecida por la viuda de García Sánchez I, Doña Endregoto Galíndez, su hijo Sancho Garcés II Abarca y su esposa Doña Urraca, al Monasterio de Siresa, de la villa de Szaberri (o también Exabierri a Martz), con todas sus casas, montes, viñedos, etc. El término de Javierremartés se encuentra en la actualidad despoblado, cerca de Martés.

Según la documentación consultada, durante el siglo $x$ tenemos constancia de la existencia de viñedo en los sectores más meridionales del Valle de Hecho y Valle de Ansó, así como en La Canal de Berdún.

\section{TOPÓNIMOS CON VIÑEDOS MENCIONADOS EN EL SIGLO XI}

Las referencias a viñedos durante el siglo XI son mucho más numerosas que en los siglos precedentes, y lo son también respecto a los siglos posteriores.

${ }^{8}$ San Juan de la Peña (Ubieto), doc. 16; San Juan de la Peña (MAGALLON), doc. XI.

${ }^{-}$San Juan de la Peña (UBIETo), doc. 17; San Juan de la Peña (MAGALLON), doc. X.

${ }^{10}$ Jaca: Documentos Municipales, doc. 1; Catedral de Huesca, doc. 11; Siresa, doc. 9; Cadena de Jaca, doc. 1. 
La mayoria son donaciones, tanto reales como particulares, efectuadas en un gran porcentaje a diferentes Monasterios, en su mayor parte al Monasterio de San Juan de la Peña.

Como a continuación veremos, en la documentación consultada sigue atestiguada durante el siglo xI la existencia de viñedos en las entradas del Valle de Hecho y Ansó. No obstante, el hecho más destacable durante este siglo es el predominio de las referencias a viñedos cultivados en ambos márgenes del río Aragón, es decir, en las tierras ya más favorables, desde un punto de vista agrícola, de la Canal de Berdún.

\section{a) Donaciones reales}

De mediados de siglo data la donación del Monasterio de Cella con sus viñas, tierras, etc., efectuada por el rey Ramiro I a favor del Monasterio de San Juan de la Peña ${ }^{11}$. Se trata del Monasterio de San Martín de Ciella, que fue un monumento carolingio situado en la entrada del Valle de Ansó y fundado entre los años 833-840, contemporáneo por tanto del de Siresa; hoy día no queda ningún resto arqueológico y tan sólo su nombre ha persistido como topónimo de una partida del Valle de Ansó (Durán, 1973: 14 y 92-93).

En torno a estas mismas fechas (1044) Ramiro I entrega a su criado varias propiedades (casas, tierras, viñas, etc.) en Larosse (Larués, cerca de Bailo) ${ }^{12}$; y dos años más tarde, el mismo rey de nuevo otorga al Monasterio Pinatense un casal en Paternue con sus tierras y viñas ${ }^{13}$ (hoy dia Paternoy es un lugar despoblado perteneciente al municipio de Bailo). Del año 1054, por último, data una donación, efectuada por Ramiro I a otro criado suyo, del Monasterio de San Martín de Sarasso "qui est inter Larosse et Orzasso", con sus tierras, viñas, etc., términos que se encuentran en el actual municipio de Bailo ${ }^{14}$; San Martín de Saraso más bien cabe calificarlo de eremitario o pequeño cenobio de propiedad particular, con cierta similitud a las llamadas iglesias propias (Durán, 1978: 104).

\footnotetext{
11 San Juan de la Peña (UBieto), doc. 100; Ramiro l, doc. XVIII.

12 San Juan de la Peña (UBIEto), doc. 84.

13 Ramiro I, doc. XXXVI.

14 San Juan de la Peña (UBieto), doc. 111.
} 
En el año 1066 ya el rey Sancho Ramirez otorga a unos particulares varias casas, tierras, viñas, etc. en la villa de Artaso ${ }^{15}$. Las viñas de este mismo lugar, hoy desaparecido - cerca de Berdún-, se vuelven a mencionar nuevamente en el año 1093, al hacer donación el rey Sancho Ramírez a la iglesia de San Martín de Biel, entre otras concesiones, de las décimas y primicias de sus labranzas y viñas de Artasso ${ }^{16}$.

En un documento posiblemente fechado en el año 1076, por el que se instituye la regla de San Agustín en la Catedral de Jaca, vuelven a ser mencionados, entre otros muchos lugares con viñedo que no afectan en concreto a este sector occidental de la comarca jacetana que ahora estamos estudiando, las viñas, campos, montes y valles de Siresa ${ }^{17}$.

Finalmente, Sancho Ramírez, rey de Aragón y Navarra, y su hijo Pedro donan en 1093 al Monasterio de Montearagón el Monasterio de San Pedro de Siresa, con todas sus viñas y demás bienes ${ }^{18}$. Es la suerte que corren la mayor parte de los monasterios pirenaicos; recordemos, por ejemplo, la incorporación al Monasterio de Montearagón, durante ese mismo año, del Monasterio de San Andrés de Fanlo ${ }^{19}$, situado a orillas del Gállego, en la comarca del Serrablo.

\section{b) Donaciones particulares}

Una gran parte del viñedo mencionado durante el siglo XI obedece a donaciones que diferentes particulares efectúan a favor, en su mayoría, del Monasterio de San Juan de la Peña. Así, este Monasterio recibe un majuelo (viña recién plantada) en Saso y otro en Tolosana ${ }^{20}$, junto con la iglesia de Santa Eufemia, situada en Biniés, con sus tierras y viñas ${ }^{21}$. Estas viñas cultivadas en torno a Biniés (Saso, Tolosana, Sta. Eufemia) se mencionan frecuentemente a lo largo del siglo $\mathrm{XI}$, e incluso estas heredades (tierras, campos, viñedos, etc.) son objeto de pleitos entre particulares y San Juan de la Peña ${ }^{22}$.

\footnotetext{
15 Sancho Ramírez (Salaraullana), doc. II.

16 Sancho Ramírez (SalarRullana), doc. XLIX.

17 Catedral de Huesca, doc. 39; Cadena de Jaca, doc. VI.

${ }^{18}$ Catedral de Huesca, doc. 55.

19 Fanlo, doc. 55.

${ }^{20}$ Ramiro I, doc. XXXVIII; Sancho Ramirez (IBARRA), doc. LXI.

21 Ramiro I, doc. XXXVIII y doc. XLVI.

${ }^{22}$ San Juan de la Peña (Ubieto), doc. 98.
} 
El Monasterio Pinatense recibe también el Monasterio de San Emeterio con todas sus tierras, huertos, viñas, etc. ${ }^{23}$; unos mezquinos en Boliola (entre el río Aragón y Martés), con sus palacios, tierras, viñas, etc. ${ }^{24}$; la villa de Votia con sus huertos y viñas ${ }^{25}$; y la iglesia de Santa Maria de Bagone, con sus tierras, viñas y demás heredades ${ }^{26}$.

Por otra parte, en un documento fechado entre los años 1035-1064 (reinado de Ramiro I), un particular entrega al Monasterio de San Justo del Val todo cuanto tenía en Berbues, especificando el viñedo entre sus posesiones ${ }^{27}$. $Y$ en el año 1086 otro particular entrega al Monasterio de San Martín de Cillas todo cuanto poseía en Ortulo: viñas, casas, tierras, etc. ${ }^{28}$.

Destaca, por último, un documento fechado el año 1072 según el cual el abad del Monasterio de San Andrés de Fanlo concede al Monasterio de San Juan de la Peña una casa con sus heredades (entre las que se menciona el viñedo) que poseía en Bagilo, en agradecimiento a la acogida que le habian dispensado ${ }^{29}$.

\section{c) Testamentos y otras disposiciones}

En un testamento otorgado por el conde Sancho Galíndez a favor del Monasterio Pinatense se menciona, entre otras muchas donaciones de viñedos fuera de los límites de la comarca objeto de este estudio, una viña en Paternue, unas viñas en Bagilo y un majuelo cerca de Berbues ${ }^{30}$.

$Y$ en un segundo testamento efectuado por Ramiro I de Aragón en el año 1061, entre otras disposiciones otorga al Monasterio de San Juan de la Peña el Monasterio de Santo Ángel de Mazones, con sus tierras y viñas $^{31}$.

Del año 1042 data una sentencia, otorgada por Ramiro I en favor del Monasterio Pinatense, confirmatoria de la donación que hizo un particular a

\footnotetext{
${ }^{23}$ Sancho Ramírez (IBARRA), doc. LXX.

${ }^{24}$ San Juan de la Peña (UBIETo), doc. 61.

${ }^{25}$ San Juan de la Peña (UBIeto), doc. 41.

${ }^{26}$ Ramiro l, doc. XCVIII; San Juan de la Peña (UBIETo), doc. 157.

${ }^{27}$ San Juan de la Peña (UBieto), doc. 177.

za Sancho Ramírez (IBARAA), doc. LXVIII.

${ }^{29}$ Fanlo, doc. 60; Sancho Ramirez (IBARRA), doc. XXXVI.

30 Sancho Ramírez (IBARRA), doc. L.

${ }^{31}$ San Juan de la Peña (UBIeto), doc. 159; Ramiro I, doc. C.
} 
dicho Monasterio de los bienes que poseía en Biniesse y Beralabilla, entre los que se especifica la existencia de viñedo en dichos términos ${ }^{32}$.

En una escritura de avenencia, sin fecha, entre el Monasterio de San Juan de la Peña y un particular, se mencionan unas viñas en Lecueyta y Gissu, y unos majuelos en el valle de Laruesa $^{33}$.

\section{d) Compra-venta de viñas y contratos de plantación}

Resulta interesante un documento de escritura de compra, fechado en el año 1084, donde consta la adquisición a unos particulares, por parte del Monasterio Pinatense, de dos aranzadas de viña en el lugar de Barbarin, en el término de Bagilo ${ }^{34}$. Esta es una de las escasísimas noticias en las que se especifica la extensión del viñedo.

Es también muy interesante un documento del año 1074 en el que el rey Sancho Ramírez otorga a su eitane, entre otras posesiones, una finca rústica en Baylo, para que plante viñas, quedando la mitad para él y la otra mitad para el rey ${ }^{35}$. Es un tipo de contrato muy parecido a los "complant" franceses, en los que no se dividen los frutos de la donación, sino la propia viña en dos partes iguales (Benito, 1963: 57); la existencia de esta forma de contrato está también atestiguada en la comarca del Serrablo a fines del siglo $\mathrm{XI}$ y principios del siglo $\mathrm{XII}^{36}$.

\section{TOPÓNIMOS CON VIÑEDO MENCIONADOS EN LOS SIGLOS XII Y XIII}

Durante la Baja Edad Media son ya muy escasas las referencias a viñedos en la comarca occidental jacetana según las fuentes documentales consultadas.

\footnotetext{
${ }^{32}$ San Juan de la Peña (UBIETo), doc. 79; Ramiro I, doc. XX y doc. CXVI.

33 Sancho Ramírez, (IBARRA), doc. LXXXV.

34 Sancho Ramírez, (IBARRA), doc. LXII.

35 Sancho Ramirez, (SalarRullana), doc. IX.

36 Fanlo, doc. 72 y doc. 93. Véase también Ubieto, 1951, doc. 103.
} 
Excepto un documento de compraventa entre dos particulares de una heredad en Orzas, en la que se menciona el viñedo ${ }^{37}$, el resto son donaciones a favor de diferentes Monasterios. El Monasterio de San Pedro de Siresa recibe varios huertos, viñas, campos, etc., en Binies, Brallavilla y Berdum ${ }^{38}$, el Monasterio de San Juan de la Peña una viña cerca de Ordues ${ }^{39}$, y el Monasterio de Santa Cruz de la Serós recibe de su abadesa la heredad que tenía en Bagone, con sus huertos, viñas, etc. ${ }^{40}$.

Por último, en un documento fechado a principios del siglo XIII, el obispo de Huesca dona a un particular una heredad, con sus campos, viñas, etc. que el Monasterio de San Pedro de Siresa tenía en Binies ${ }^{41}$.

\section{CONCLUSIONES}

La documentación consultada nos atestigua, desde fecha muy temprana, la existencia de viñedos cultivados no sólo en la depresión intramontana de la Canal de Berdún, sino también en sectores muy septentrionales de estos valles pirenaicos altoaragoneses.

Durante los siglos $\mathrm{Ix}$ y $\mathrm{x}, \mathrm{y}$ de acuerdo con el momento político por el que la región atravesaba, resulta lógico que estas gentes, recluidas en las montañas, practicaran forzosamente una economía de autosubsistencia, sin más comercio que el indispensable para satisfacer las necesidades naturales. Sin duda, este viñedo se localizaba en zonas abrigadas y soledas, - cuanto más al Norte más acantonados en las solanas y carasoles-, como lo demuestra un documento fechado a mediados del siglo IX: «donamus unam terram... in parte solana, pro vinea ponenda" (véase nota 7).

Conforme la Reconquista va avanzando, disminuyen las referencias a aquellos viñedos cultivados en los altos valles pirenaicos occidentales aragoneses, mientras que se intensifican los datos relativos a su cultivo

\footnotetext{
${ }^{37}$ Catedral de Huesca, doc. 150.

38 Catedral de Huesca, doc. 118.

39 San Juan de la Peña, (CAnellas), doc. CCVIII.

40 Santa Cruz de la Serós, doc. 37.

${ }^{41}$ Catedral de Huesca, doc. 612.
} 
en la depresión intrapirenaica de La Canal, fundamentalmente durante el siglo $\mathrm{xl}$.

Más adelante, a finales ya de la Edad Media, estos viñedos de los Llanos de la Canal van dejando paulatinamente de mencionarse en las fuentes documentales, en favor de los cultivos del Somontano, cuyos problemas de repoblación, en todos los ámbitos, quedan ampliamente reflejados en la documentación de la época.

Como es lógico, con ello no queremos decir que se abandonen todos estos viñedos cultivados en ambas márgenes del río Aragón, sino que, por motivos de diversa índole, su cultivo deja de mencionarse en las fuentes documentales, como debió ocurrir con muchos otros viñedos no atestiguados en la documentación pero, sin duda, existentes.

Incluimos un índice toponímico de aquellos lugares en los que queda atestiguada la existencia de viñedos. En primer lugar, presentamos el topónimo transcrito tal y como aparece en el documento; entre paréntesis queda reflejada la fuente documental, el número del documento y la fecha; a continuación, el nombre actual de topónimo y el término municipal al que hoy día pertenece. Añadimos una interrogación en todos aquellos casos cuya localización no es segura.

Los topónimos en los que se menciona la existencia de viñedo aparecen reflejados en el mapa adjunto. 
Topónimos en los que queda atestiguada la existencia de viñedos en las fuentes documentales (siglos IX al XIII).

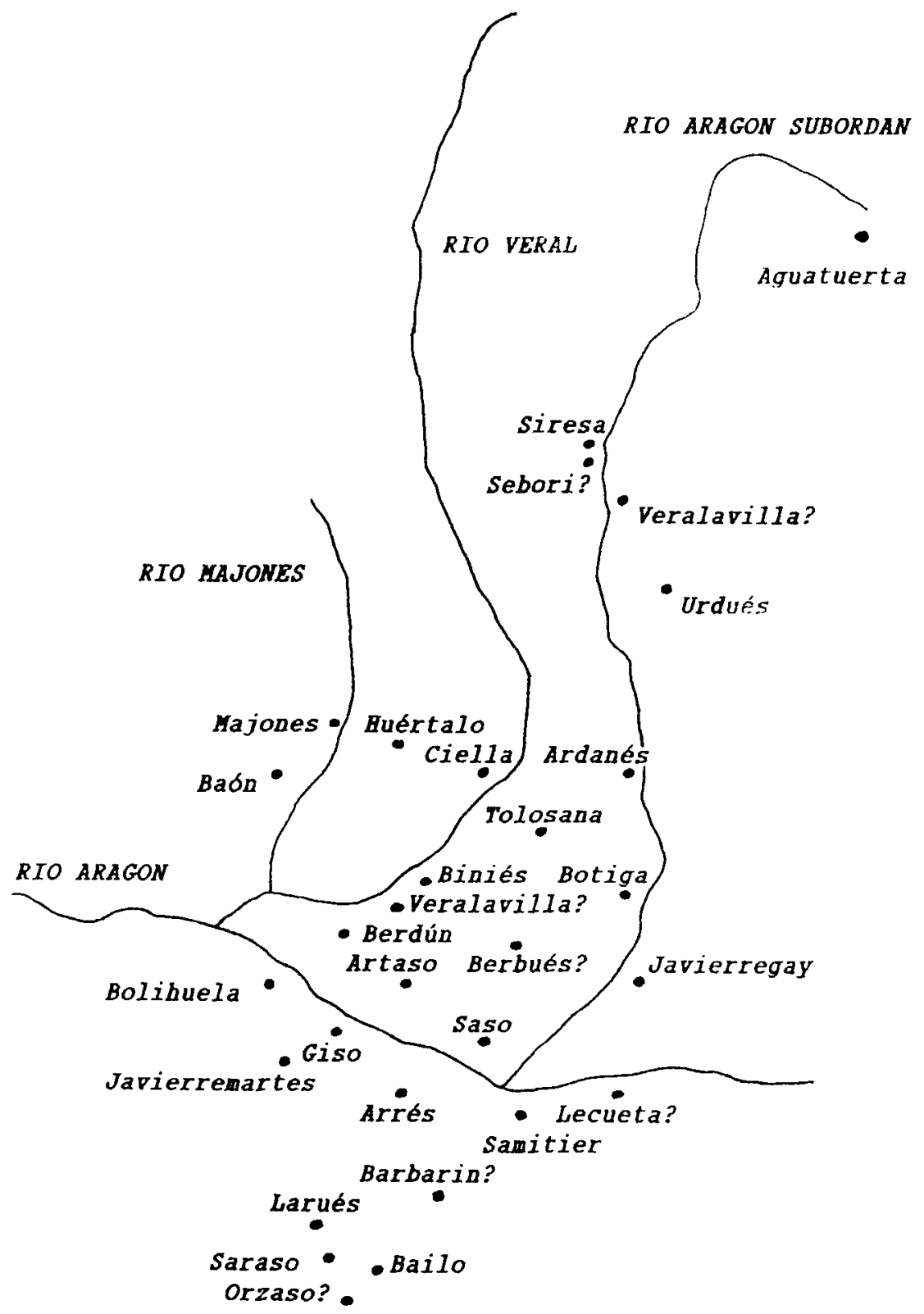

- Paternoy 


\section{ÍNDICE TOPONIMICO DE LOS LUGARES CON VIÑEDO MENCIONADOS EN LAS FUENTES Y SU LOCALIZACIÓN ACTUAL}

AQUATORTA (Siresa, doc. 4, año 867): Aguatuerta, desaparecido en el nacimiento del río Aragón Subordán.

ARDENES (San Juan de la Peña [UBieto], doc. 17, año 947; San Juan de la Peña [MAgallón], doc. X, año 947): Ardanés, despoblado en término de Embún (UBIETo, 1972), en el municipio del Valle de Hecho.

ARRAISE (San Juan de la Peña [Ubieto], doc. 5, año ca. 850): Arrés, lugar del municipio de Bailo.

ARTASO (Sancho Ramírez [SalarRullana], doc. II, año 1066): Artaso, desaparecido cerca de Berdún, en el municipio de La Canal de Berdún.

ARTASSO (Sancho Ramírez [SalARRUANA], doc. XLIX, año 1093): véase ARTASO.

BAGONE (Ramiro l, doc. XCVIII, año 1060; San Juan de la Peña [UBIETo], doc. 157, año 1060; Santa Cruz de la Serós, doc. 37, año 1170): Baón, despoblado entre Asoveral y Majones, cerca de Villarreal de La Canal, en el actual municipio de La Canal de Berdún.

BAGILO (Fanlo, doc. 60, año 1072; Sancho Ramírez [lBaRRA], doc. XXXVI, año 1072 y doc. L, año 1080): Bailo.

BARBARÍN (Sancho Ramírez [IBARRA], doc. LXII, año 1084): Barbarín, despoblado en término de Bailo.

BAYLO (Sancho Ramírez [SALARRULLANA], doc. IX, año 1074): véase BAGILO. 
BERALABILLA (Ramiro I, doc. XX, año 1042): Veralavilla, topónimo cerca de Biniés (UBIETo, 1972; DURÁN, 1961); lugar junto a Hecho (SA. LARRULLANA, 1907; IBARRA, 1913).

BERALE BILla (San Juan de la Peña [Ubieto], doc. 79, año 1042): véase BERALABILLA.

BERALE VILLA (Ramiro l, doc. CXVI, sin fecha): véase BERALABILLA.

BERBUES (San Juan de la Peña [Ubieto], doc. 177, año 1035-1064; Sancho Ramírez [IBARRA], doc. L, año 1080): Berbués, despoblado cerca de Santa Engracia, lugar del municipio de Puente la Reina de Jaca.

BERDUM (Catedral de Huesca, doc. 118, año 1114-1115?): Berdún, capital del municipio de Canal de Berdún.

BINIES (San Juan de la Peña (UBIETO), doc. 16, año 947; San Juan de la Peña (MAGALLON), doc. XI, año 947; Catedral de Huesca, doc. 118, año 1114-1115?; Catedral de Huesca, doc. 612, año 1202): Binies, lugar perteneciente al mun. de La Canal de Berdún.

BINIESE (San Juan de la Peña [UBieto], doc. 79, año 1042; Ramiro I, doc. XX, año 1042 y doc. CXVI, sin fecha): véase BINIES.

BOLIOLA (San Juan de la Peña [Ubieto], doc. 61, año 1033): Bolihuela, despoblado entre el río Aragón y Martés, cerca de Martés, en el municipio de La Canal de Berdún.

BORBOSSE (Siresa, doc. 1, año 814-839; Catedral de Huesca, doc. 3, año 833): véase BERBUES.

BRALLAVILLA (Catedral de Huesca, doc. 118, año 1114-1115?): véase BERALABILLA.

Cella (San Juan de la Peña [Ubieto] doc. 100, año 1049; Ramiro l, doc. XVIII, año 1041): Ciella, Monasterio bajo la advocación de San Martín, que estaba situado en la entrada del Valle de Ansó, cerca de la Foz de Biniés, fundado en la primera mitad del siglo $\mathrm{x}$, y por tanto contemporáneo del de Siresa (DURÁN, 1973, p. 14 y 92-93).

EXABIERRI A MARTZ (Cadena de Jaca, doc. 1, año 971): Javierremartés, despoblado cerca de Martés, lugar del municipio de La Canal de Berdún.

GISSU (Sancho Ramírez [IBARRA], doc. LXXXV, sin fecha): Giso, desaparecido entre Arrés y Martés, en el actual municipio de Canal de Berdún. 
HIGIREM (Siresa, doc. 1, año 814-839; Catedral de Huesca, doc. 3, año 833): Higirem, posiblemente se trate de un topónimo, hoy desaparecido, en el Valle de Hecho.

ISXAVIERRE GAYO (Siresa, doc. 4, año 867): Javierregay, lugar del municipio de Puente la Reina de Jaca.

LAROSSE (San Juan de la Peña [Ubieto], doc. 84, año 1044): Larués, lugar perteneciente al municipio de Bailo.

LARUESA (Sancho Ramírez [IBARRA], doc. LXXXV, sin fecha): véase LAROSSE.

LECUEYTA (Sancho Ramírez [IBARRA], doc. LXXXV, sin fecha): Lecueta, despoblado cerca de Berbusa (SALARRULLANA, 1907; IBARRA, 1913); villa desaparecida entre Santa Cilia y Badaguás (UBIETo, 1962); topónimo situado entre Arrés y Binacua (Asso, 1947).

MAZONES (San Juan de la Peña [Ubieto], doc. 159, año 1061; Ramiro I, doc. C. año 1061): Majones, lugar del municipio de La Canal de Berdún.

OLEDOLA (Catedral de Huesca, doc. 7, año 867): Oledola, posiblemente se trate de un topónimo, hoy desaparecido, en el Valle de Hecho.

ORDUES (San Juan de la Peña [CANeLLAS], doc. CCVIII, año 1165): Urdués, lugar del municipio del Valle de Hecho.

ORTULO (Sancho Ramírez [lBarRa], doc. LXVIII, año 1086): Huértalo, lugar despoblado perteneciente al municipio de La Canal de Berdún.

ORZAS (Catedral de Huesca, doc. 150, año 1139): Orzaso, despoblado en término de Larués, lugar del municipio de Bailo.

PATERNUE (Ramiro I, doc. XXXVI, año 1046; Sancho Ramirez [IBARRA], doc. L, año 1080): Paternoy, lugar despoblado perteneciente al municipio de Bailo.

SAN EMETERIO (Sancho Ramírez [IBARRA] doc. LXX, 1087): Samitier, en el municipio de Bailo.

SAN PEDRO DE SIRESA (Catedral de Huesca, doc. 55, año 1093): Siresa, lugar perteneciente al municipio del Valle de Hecho.

SANTA EUFEMIA (Ramiro l, doc. XXXVIII, año 1046 y doc. XLVI, año 1049; San Juan de la Peña [UBIETo], doc. 98, año 1049): Santa Eufemia, Monasterio situado en Biniés, lugar del municipio de La Canal de Berdún. 
SARASSO (San Juan de la Peña [Ubieto], doc. 111, año 1054): Saraso, Monasterio de San Martín de Saraso, despoblado en término de Larués, en las cercanias de dicha villa, en el actual municipio de Bailo.

SASO (Ramiro I, doc. XXXVIII, año 1046; San Juan de la Peña [UBieto], doc. 98, año 1049; Sancho Ramírez [IBARRA], doc. LXI, 1084): Saso, en término de Biniés, lugar del municipio de La Canal de Berdún.

SEBORI (Catedral de Huesca, doc. 4, año [833-850]); Siresa, doc. 11, siglo x): Sebori, topónimo muy repetido en la cuenca del río Aragón Subordán, posiblemente el lugar donde se levantó el Monasterio de San Pedro de Siresa.

SIRESA (Catedral de Huesca, doc. 39, año 1076?; Cadena de Jaca, doc. VI, año 1076?): Siresa, lugar del municipio del Valle de Hecho.

SZABERRI (Jaca: Documentos Municipales, doc. 1, año 971; Catedral de Huesca, doc. 11, año 971; Siresa, doc. 9, año 971): Javierremartés, despoblado, cerca de Martés, lugar del municipio de La Canal de Berdún.

TOLOSANA (Ramiro l, doc. XXXVIII, año 1046; San Juan de la Peña [UBIETO], doc. 98, año 1049; Sancho Ramírez [IBARRA], doc. LXI, 1084): Tolosana, cerca de Biniés, en el municipio de La Canal de Berdún.

VOTIA (San Juan de la Peña [UBieto], doc. 41, año 1025): Botiga, despoblado en el barranco de su mismo nombre, en término de Javierregay, lugar del municipio de Puente la Reina de Jaca. 


\section{BIBLIOGRAFÍA}

\section{Fuentes documentales}

Canellas LOPEZ, A., 1964: “Colección Diplomática de San Andrés de Fanlo (958-1270)". En Institución "Fernando el Católico». Zaragoza, CSIC.

Canellas Lopez, A. y Uson Sese, M., 1935: «El Libro Gótico o Cartulario de San Juan de la Peña». Revista Universidad, año XII, n. ${ }^{\circ}$. Zaragoza.

DuRÁN GUDIOL, A., 1965-1969: “Colección Diplomática de la Catedral de Huesca». En Fuentes para la Historia del Pirineo, V y VI. Zaragoza, CSIC.

IRARRA y Rodríguez, E., 1904: “Documentos correspondientes al reinado de Ramiro I, desde 1034 hasta 1063". En Colección de documentos para el estudio de la Historia de Aragón, tomo I. Zaragoza.

-1913: «Documentos correspondientes al reinado de Sancho Ramírez, desde 1063 hasta 1094. Vol. II. Documentos particulares procedentes de la Real Casa y Monasterio de San Juan de la Peña". En Colección de documentos para el estudio de la Historia de Aragón, tomo IX. Zaragoza.

Magallón y Cabrera, M., 1903-4: "Colección Diplomática de San Juan de la Peña". Anexo de la Revista de Archivos, Biblioteca y Museos. Madrid.

SALARRULlana y DE DIOS, J., 1907: “Documentos corrrespondientes al reinado de Sancho Ramírez, desde 1063 hasta 1094. Vol. I. Documentos reales procedentes de la Real Casa y Monasterio de San 
Juan de la Peña». En Colección de documentos para el estudio de la Historia de Aragón, tomo III. Zaragoza.

SAngorRin, D., 1920: «El Libro de la Cadena del Concejo de Jaca. Documentos Reales, Episcopales y Municipales de los siglos X, XI, XII, XIII, XIV". En Colección de documentos para el estudio de la Historia de Aragón, tomo XII. Zaragoza.

Ubieto ArtetA, A., 1960: "Cartulario de Siresa". Textos Medievales, n. 2. Valencia.

-1962: “Cartulario de San Juan de la Peña, l». Textos Medievales, n. 6. Valencia.

-1963: “Cartulario de San Juan de la Peña, II». Textos Medievales, n. ${ }^{\circ}$ 9. Valencia.

-1966: “Cartulario de Santa Cruz de la Serós". En Textos Medievales, n. ${ }^{\circ}$ 19. Valencia.

-1975: “Jaca: Documentos Municipales». En Textos Medievales, n. 43. Valencia.

\section{Estudios}

Alvar; M., Toponimia del Alto Valle del río Aragón. Monografías del Instituto de Estudios Pirenaicos. CSIC. Zaragoza, 1949.

Asso, I. DE: Historia de la economía política de Aragón. Zaragoza, $2 .^{a}$ ed. 1947.

BenITo VIDAL, A.: «La viña en el Somontano de Alquézar (siglos XII-XIII)», Saitabi XIII, p. 53-60, 1963.

Callizo, J.: "La Jacetania», en Geografía de Aragón. Guara Editorial, tomo 3, p. 13-61, 1984.

Durán Gudiol, A.: "Geografía medieval de los obispados de Jaca y Huesca», Argensola XII, p. 1-103, 1961.

-: Arte altoaragonés de los siglos $X$ y XI. Sabiñánigo. Caja de Ahorros y Monte de Piedad de Zaragoza, Aragón y Rioja, 1973.

-: Ramiro I de Aragón. Zaragoza. Guara editorial. Colec. Básica Aragonesa, 1978.

-: Los condados de Aragón y Sobrarbe. Zaragoza. Guara Editorial, 1988. 
Elcock, W. D.: «Toponimia menor en el Alto Aragón». Acta de la I reunión de Toponimia Pirenaica. Jaca, 1949.

García Blanco, M.: "Sufijos románicos en la toponimia aragonesa del siglo Xl". I Congreso Internacional del Pirineo. Instituto de Estudios Pirenaicos. Zaragoza. CSIC, 1952.

Ubieto ARteta, A.: Colección Diplomática de Pedro I de Aragón y Navarra. Escuela de Estudios Medievales, textos XIX. Zaragoza, 1951.

-: Toponimia aragonesa medieval. Valencia, 1972. 